\title{
Mogador, "factoría extrema" y la cuestión del comercio fenicio en la costa atlántica africana
}

\author{
Mogador, "Extreme Factory" and the Problem of the Phoenician \\ Trade in the African Atlantic Coast
}

\author{
Fernando LóPEZ PARDO \\ Publicado por primera vez en Actes du $V^{e}$ Colloque International d'Histoire et Ar- \\ chéologie de l'Afrique du Nord (Avignon, 1990), París, 1992, 277-296
}

\section{Mogador, "Factoría extrema"}

A $1000 \mathrm{~km}$ de Cádiz se encuentra el islote de Mogador el cual formaba parte de un antiguo archipiélago costero, con el peñasco donde se emplaza la actual Essaouira, que fue unido al continente africano por la acción aluvionaria del uadi Ksob (figs. 1 y 2$){ }^{1}$

\footnotetext{
1 A comienzos de los años 50, dos profesores del liceo de Essaouira, tras unos primeros hallazgos superficiales en la isla de Mogador, e interesados por la comprobación de si las "Islas Purpurarias" del rey mauritano Iuba II se encontraban allí, fueron a dar con vestigios muy anteriores, entre los que se contaban unos fragmentos de cerámica con graffiti en lengua fenicia. Su interés por los hallazgos quedó plasmado en un artículo (DesJaCques -Koeberlé 1955). R. Thouvenot dio a conocer su descubrimiento con anterioridad incluso (Thоuvenot 1954); de los sucesivos hallazgos se dio noticia en los informes arqueológicos presentados por el director de Antigüedades (THOUvENot 1954a, 56; ID. 1955-1956, 202); las excavaciones fueron encomendadas a P. Cintas que hizo una pronta comunicación de los resultados (CinTAS 1954, 42-55); dado el interés del hallazgo para los descubrimientos que en la misma época se estaban haciendo al sur de la Península Ibérica, el trabajo de P. Cintas fue reseñado por PemÁn (1955) y TARRADELL (1955); por suerte, las excavaciones fueron inmediatamente continuadas por A. Jodin, que se preocupó en ir avanzando resultados con gran asiduidad (JodIN, 1957; ID. 1957a). El primer informe preliminar, pero de gran entidad, fue sacado a la luz ese mismo año (JoDIN 1957b, 940). El trabajo definitivo en lo que nos atañe fue: Mogador, comptoir phénicien du Maroc atlantique (Jodin 1966), referido a los hallazgos de época fenicia y púnica. Publica el año siguiente la parte correspondiente a la época del reino mauritano y romana (JoDIN 1967). El interés que sigue despertando el yacimiento entre los arqueólogos españoles se demuestra por la gran cantidad de veces que los restos de Mogador son utilizados como elementos de comparación para otros yacimientos peninsulares que empiezan a ser descubiertos por esas fechas. El libro es reseñado por SANMARTí GReCo (1967). Los graffiti sobre platos y ánforas de las sucesivas excavaciones de Koerberlé, Cintas y Jodin son estudiados por J. Février en la misma época dentro de la obra de conjunto, Inscriptions antiques du Maroc, bajo el subtítulo "Inscriptions puniques et néopuniques" (FÉVRIER 1966). Si el interés suscitado por el yacimiento de Mogador ha sido grande, en cambio los intentos por integrarlo coherentemente en la interpretación de lo que fue la expansión fenicia en Occidente han sido muy pobres, limitándose la mayoría de las veces en los trabajos de tipo arqueológico e histórico a poner en evidencia los parecidos o discordancias entre materiales. Un lamento por este escaso eco científico se puede apreciar en la desilusión de A. Jodin, la persona que ha hecho mayores esfuerzos para dar a conocer los hallazgos de Mogador, cuando comenta la aparición de la obra de compendio de CinTAS (1970), que no se hace eco de los descubrimientos de Mogador, ni de nada del resto del Marruecos fenicio (Jodin 1978).
} 


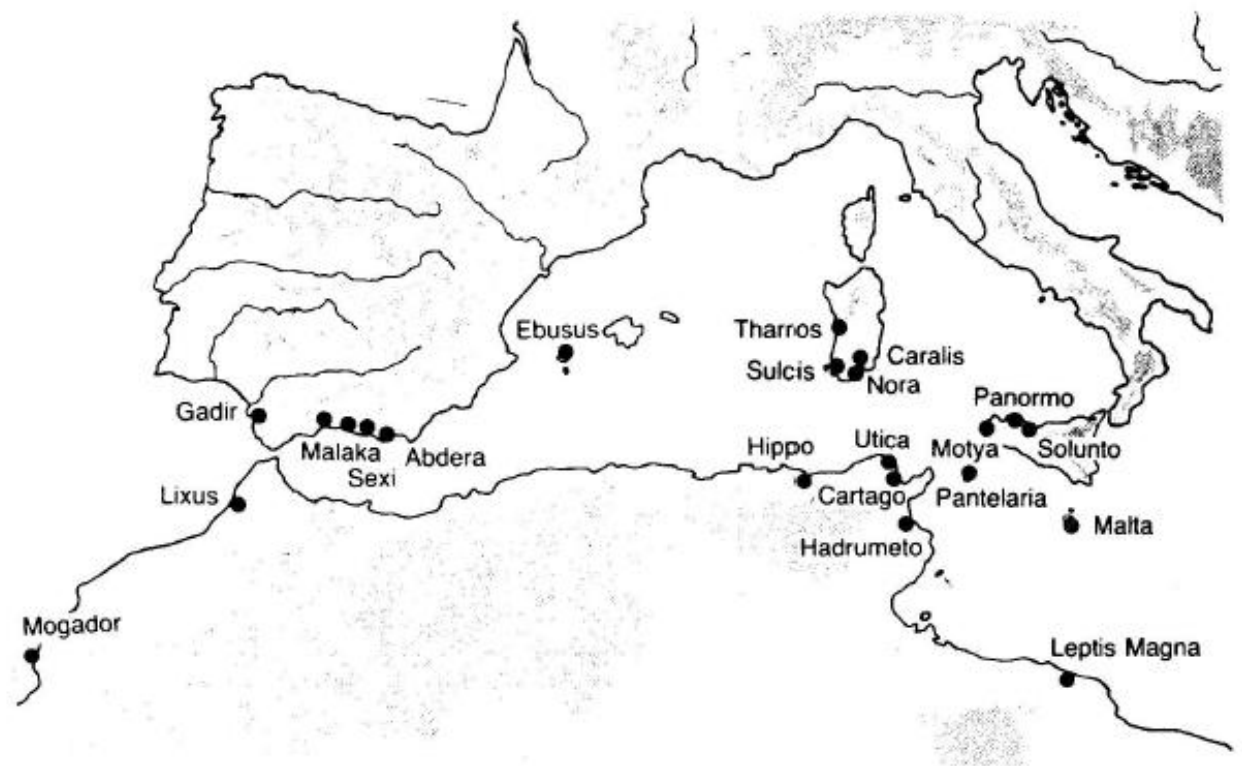

Fig. 1. Mogador y la expansión fenicia en el Mediterráneo occidental (según M.E. Aubet, Tiro y las colonias fenicias de Occidente, Barcelona, 1989, 141, fig. 22).

Estos dos islotes junto con el de Mohamedia, cerca de Casablanca, eran los únicos, prácticamente a lo largo de toda la costa atlántica. ${ }^{2}$ Mogador era pues uno de los escasísimos lugares de esta línea costera donde los fenicios podían emplazarse según la forma tradicional de abordamiento de una costa ignota por parte de estos navegantes-mercaderes. Esta forma de instalación en un islote garantizaba la seguridad personal de los comerciantes y servía de lugar de almacenamiento temporal de las mercancías.

Por ello y debido al escaso cauce del uadi Ksob y su escasa zona de penetración, creemos que la factoría de Mogador no se debe a su fachada inmediata, el valle del Ksob, sino a un espacio mucho más amplio que debió incluir sin duda el cabo Ghir y el valle del Sous.

En este sentido es extraordinario el paralelismo que se puede establecer entre el establecimiento de Mogador y la realidad que se trasluce en las tentativas de la fundación de Gadir. El relato nos refiere que los marinos tirios se instalaron primero en un islote excesivamente alejado de las explotaciones mineras, en Sexi, que en esa época era un islote apenas separado de la línea de costa. Después se situaron en un lugar demasiado próximo al mercado indígena, seguramente en una isla cercana a Huelva, y finalmente en un archipiélago lo suficientemente alejado de la desembocadura del

2 Todo ello según Jodin 1966, 5. 


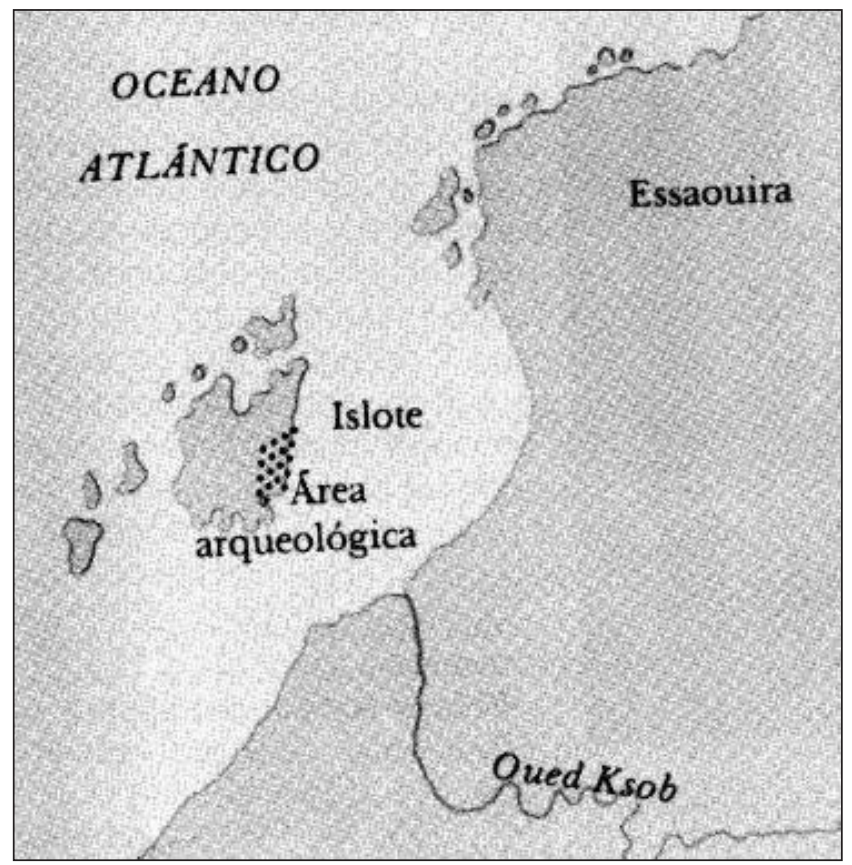

Fig. 2. El islote de Mogador (según S. Moscati (dir.), Los fenicios. Barcelona, 1988, 180).

Guadalquivir y de Huelva, tanto para no molestar a los indígenas como para no entorpecer el trasiego comercial. Suponemos que ambas fundaciones se rigieron por las mismas necesidades mercantiles. ${ }^{3}$

La ocupación del islote de Mogador tuvo lugar en la primera mitad del s. VII a.C. y a pesar de que duró hasta mediados del s. VI a.C. no llegó nunca a tener carácter permanente. Ni P. Cintas, ni A. Jodin pudieron reconocer ningún muro de la época, ni siquiera de adobes. Sólo detectaron la existencia de hogares y algunos suelos de arcilla apisonada. ${ }^{4}$

El hábitat fue seguramente en tiendas, como el que describe el Periplo de Escílax para los comerciantes fenicios que llegan a la isla de Cerné, o en último caso en chozas de ramaje.

El único elemento de piedra es un pilar cuadrangular, con la base más ancha, de $1.47 \mathrm{~m}$ de alto. Tal hallazgo hizo ya sugerir a A. Jodin que se trataba de un monolito de función cultual. S. Moscati reafirmó el carácter religioso del bloque, y lo equiparó

3 Str. III, $5,5$.

4 A. Jodin entendía que la vida de la factoría fenicia de Mogador duró aproximadamente un siglo, desde mediados del s. VII hasta mediados del s. VI a.C. Los niveles arqueológicos fenicios, al asentarse directamente sobre suelo virgen, y al haber un posterior abandono muy largo, no cuentan con elementos intrusivos que hubieran distorsionado la datación sugerida (Jodin 1966, 48-49). Solamente es posible, si aceptamos las nuevas fechas propuestas para algunas formas cerámicas, que la evidencia de las primeras escalas en Mogador pueda remontarse hasta el 700 a.C. (cfr. RuIz MATA 1986, 251). 


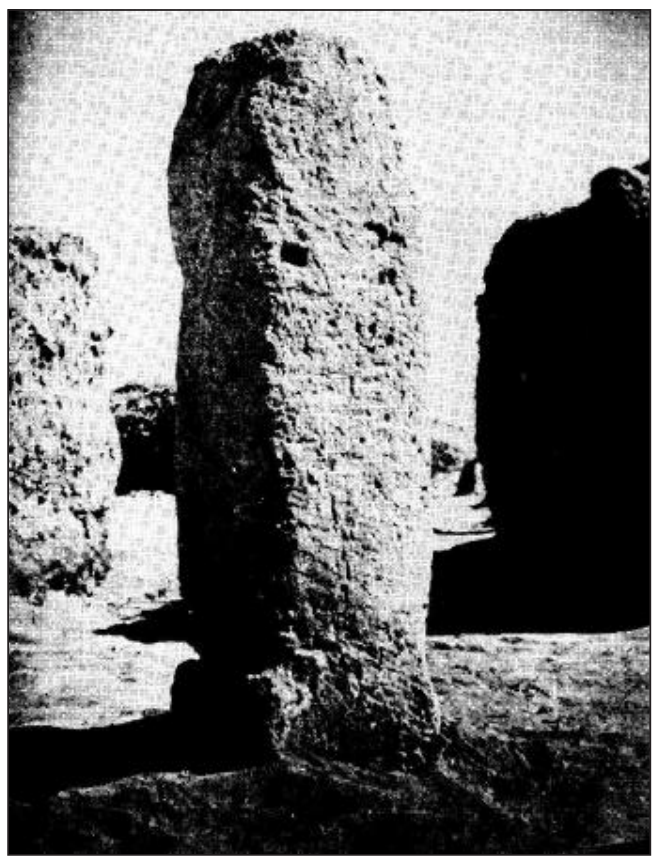

Fig. 3. Monolito hallado en la excavación de Mogador. (Según A. Jodin, Mogador, comptoir phénicien du Maroc atlanique. Rabat, 1966, 50, fig. 16).

a otro aparecido en Monte Sirai (Cerdeña) (fig. 3). ${ }^{5}$ El hallazgo se inserta perfectamente en la costumbre fenicia de elevar un ara o recinto sagrado en las escalas de su expansión comercial.

La permanencia durante más de un centenar de años de un hábitat sin construcciones fijas así como las peculiaridades de sus hallazgos nos hacen reconocer a Mogador como una factoría en el sentido más riguroso del término: un establecimiento comercial con lugares de almacenaje, en el que residen temporal o permanentemente agentes de comercio. ${ }^{6}$

La tipología de los materiales y sus peculiares proporciones en el yacimiento están determinadas por el carácter de Mogador como factoría extrema, diferenciándose netamente de lo que aparece en otros establecimientos fenicios, como colonias "de poblamiento", escalas marítimas o factorías más consolidadas.

5 Jodin 1966, 52; Moscati 1988, 288.

6 El hallazgo de restos de ballena y de pescado me parece totalmente insuficiente para considerar Mogador como una estación pesquera. Así lo llega a considerar por un momento AuBET 1987, 254. Una interpretación en este sentido nos obligaría a creer que existió una intensa colonización fenicia a lo largo de la costa africana que justificase un asentamiento pesquero tan al sur. Tampoco es conocida para el s. VII a.C. la existencia de establecimientos fenicios fundamentalmente dedicados a la pesca, ni de factorías de salazones en Occidente, para cuya producción se requiere salinas y hornos de ánforas, además de la propia fábrica de salazones. En Occidente su introducción se produjo en el s. VI a.C. (MuÑoz - BERRIATUA 1988). 
Un primer indicio es el hecho de que sólo un 5\% del total de la cerámica hallada es cerámica fina. ${ }^{7}$

De este grupo, casi la totalidad de la vajilla de mesa es engobada en rojo. Se encuentran platos de labio bastante ancho, normalmente mayor de $3,5 \mathrm{~cm}$, con borde redondeado o acanalado, y páteras o fuentes carenadas ya sea de labio recto o vuelto, y cuencos carenados y hemiesféricos. Sin embargo las fuentes de cerámica gris son muy raras, habiéndose recogido sólo 10 fragmentos. ${ }^{8}$

En este conjunto hay que incluir las copas con decoración de círculos concéntricos de las que se han recogido 7 trozos. Entre ellas, A. Jodin distingue dos tipos según la calidad del tratamiento de la superficie. Las más finas están cubiertas de un engobe blanco con zonas lustradas en rojo y en las otras la pintura negra y roja es aplicada directamente sobre la pasta, bastante granulosa. ${ }^{9}$

También entre las cerámicas de uso podemos incluir las lámparas de aceite, todas ellas bicornes, así como dos quemaperfumes de dos pisos. ${ }^{10}$ Dichos objetos nos recuerdan sin duda el ambiente gaditano.

El lote abrumadoramente mayoritario está formado por los recipientes de almacenaje. Así por ejemplo los pequeños contenedores están magníficamente representados en Mogador. Los frascos de aceite perfumado encontrados son 34 como mínimo. En ellos ha sido posible reconocer formas de la segunda facies difundida en Occidente desde mediados del s. VII a.C. y algunos probablemente de la primera, ss. VIII-VII a.C. Menos abundantes son los jarros de boca de seta y jarras piriformes de borde trilobulado. ${ }^{11}$

Los contenedores medianos están bien atestiguados tanto en cantidad como en variedad de formas. No podemos, sin embargo, discernir cuáles de ellos han sido transportados allí para su uso como jarras (o sea, vacíos) y cuáles estaban llenos. Menos aún sabemos de su posible contenido.

Se han hallado algunas jarras-ánforas de barniz rojo. También recipientes de cuello estrecho, unos con engobe, otros sin é1, y otros, en suma, con decoración lineal. Entre los bordes se han podido reconocer algunos con baquetón a media altura del cuello que se relacionan sin duda con los aparecidos en Cruz del Negro (Carmona). ${ }^{12}$

Los contenedores de cuello ancho suelen ser de pasta menos depurada que los anteriores, entre ellos son señalables los de cuatro asas, muy comunes en los yacimientos del sur de la Península Ibérica. ${ }^{13}$

A este grupo de contenedores intermedios pertenecen sin duda varios fragmentos de cerámica pintada de círculos concéntricos, correspondientes al tipo Bichrome IV de Chipre, que también se documenta en el yacimiento de Toscanos. ${ }^{14}$

7 JodIN, 1966, 53.

8 Jodin, 1966, 77-91 y 147; CinTAs 1954, 45-50.

9 JoDIN 1966, 161-163.

10 CinTAS, 1954, 50-51; Jodin 1966, 93-106.

11 Jodin 1966, 11-116 y 141-147; RAMÓn 1982; Niemeyer - SCHUbart 1969, 105.

12 Jodin 1966, 91-93 y 149-153; Cintas 1954, 52-53; Aubet 1986, 116; Aranegui 1980; Bisi 1968.

13 JoDIN 1966, 155-160.

14 JodIN 1966, 163-166; ID. 1978, 76. 


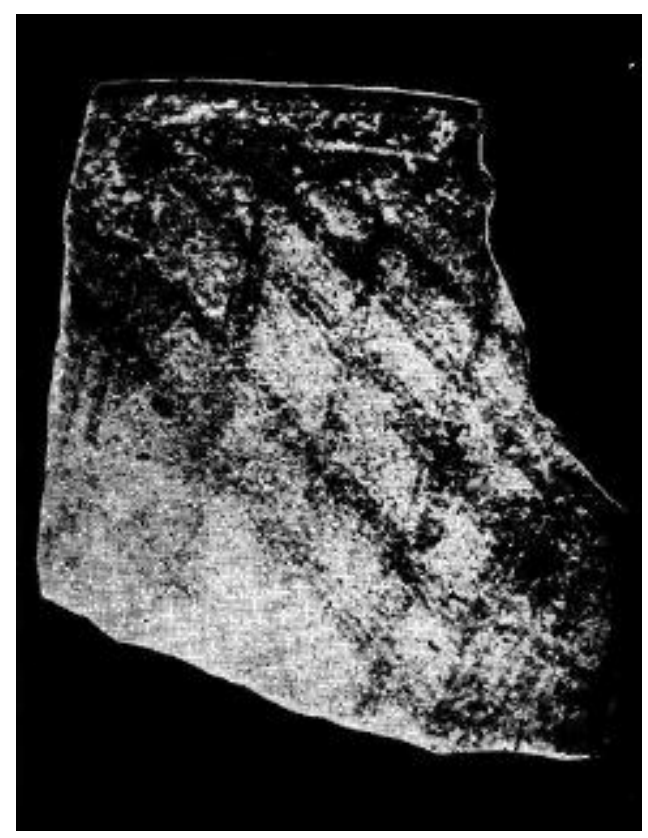

Fig. 4. Fragmento de cuenco de "retícula bruñida" de Mogador (según A. Jodin, Mogador, comptoir..., 167, fig.46).

De los grandes recipientes, muy abundantes, la mayor parte son ánforas fenicias globulares. Les acompañan los trípodes, seguramente para apoyarlas, aunque quizá sean morteros, en cuyo caso habría que incluirlos en el grupo de la cerámica de uso. Se han hallado también ánforas áticas llamadas SOS y un asa de ánfora quiota. ${ }^{15}$

Un fragmento de cuenco de "retícula bruñida" procedente del Bajo Guadalquivir o Huelva, ha sido encontrado en Mogador. ${ }^{16}$ Clara evidencia de las relaciones privilegiadas de Mogador con Gadir (fig. 4).

Junto a la cerámica a torno importada aparece otra hecha a mano, que por desgracia no ha sido publicada aún. Parece tratarse sobre todo de grandes marmitas de fondo plano, que muestran huellas de haber estado sobre el fuego. Algunas cuentan con gruesas asas aplicadas y la decoración suele ser de cordones digitados, vaciados e incisiones. Su parecido con la encontrada en otros yacimientos protohistóricos como El Khri, Dar-es-Soltan y Temara, impide considerarlas como cerámica de urgencia hecha por los fenicios. ${ }^{17}$

Además de ello, la producción a mano in situ está documentada. Se han encontrado lámparas modeladas imitando las lámparas bicornes a torno. ${ }^{18}$

15 Cintas 1954, 52-53; Jodin 1966, 61-63 y 123-132; ID. 1967, 35-37; ID. 1978, 76. Ambos tipos aparecen también en el yacimiento de Toscanos (NIEMEYER 1983, 253-254).

16 Jodin 1966, 167 y lám. XLVI.

17 Cintas 1954, 42; Jodin 1967, 37-38; ID. 1966a, 166-168.

18 JodIN 1966, 167-168. 


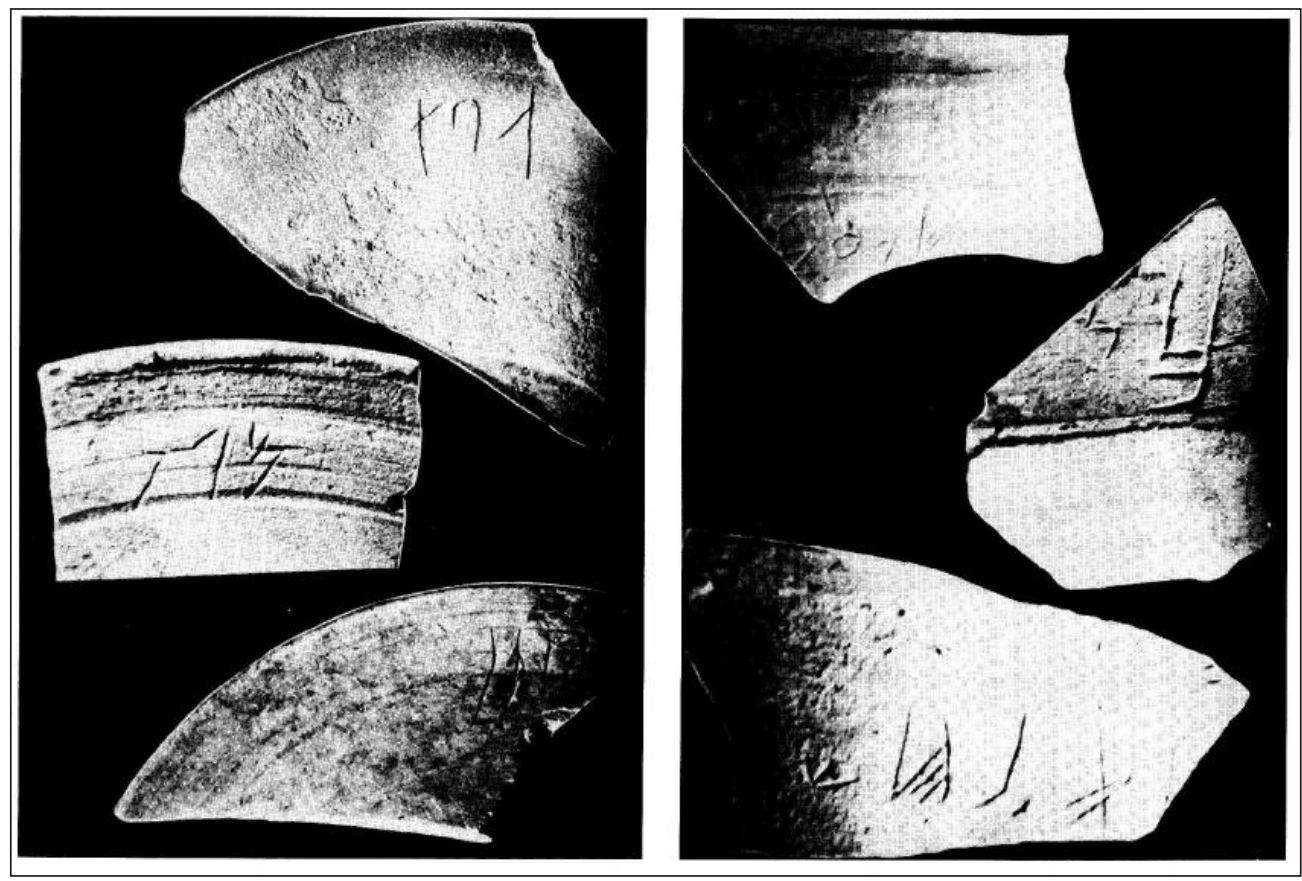

Fig. 5. Graffiti fenicios sobre platos y ánforas de Mogador (según A. Jodin, Mogador, comptoir..., 179, fig. 51; 182, fig.52).

Los objetos de metal son francamente escasos. Elementos de adorno personal, como dos pasadores, un colgante de campanita y dos pendientes, todo en cobre o bronce. En el apartado de instrumentos, sólo un anzuelo de cobre. ${ }^{19}$

La aparición de algunos fragmentos informes de bronce y de dos toberas para fuelle, una simple y otra doble, señalan la existencia de una forja en el lugar, creemos que fundamentalmente reparadora. Su forma es similar a las aparecidas en Morro de Mezquitilla, Toscanos y Cerro Salomón. ${ }^{20}$

Aparte de la cerámica a mano, sólo otro producto adquirido a los indígenas ha sido documentado arqueológicamente, las cáscaras de huevos de avestruz. ${ }^{21}$

Este abrumador predominio de los contenedores de productos sobre la cerámica de usos, es una característica propia de las factorías, donde la mayor parte de los productos van destinados al comercio con los indígenas y la utilización de platos y cuencos es significativamente menor, en porcentaje, respecto a los contenedores que en otro tipo de establecimiento colonial, como corresponde a una instalación precaria y seguramente sin estructura familiar.

19 Jodin 1966, 173-175; CinTas 1954, 54; Quillard 1979, 107-108.

20 Cfr. Jodin 1978, 173-175; 1966a, 141 y lám 36; SchubART 1986, 83.

21 CinTAs 1954, 52-53. 
También por este carácter de "factoría extrema" los fenicios completan el ajuar doméstico o incluso traen algún alimento de los mercados indígenas de la zona, como muestran los restos arqueológicos. Sólo cuando un recipiente, por su especial forma y utilidad no se encuentra en el mercado autóctono, éste se reproduce precariamente en la isla.

También por los mismos motivos podemos explicar los cuantiosos fragmentos de cerámica con letras y nombres escritos de Mogador. ${ }^{22}$

La primera particularidad de estos graffiti es que todos ellos son solamente letras o signos sueltos, o nombres de personas, la mayoría de ellos teóforos, como es frecuente entre fenicios y púnicos.

La segunda particularidad que podemos señalar es que dentro del total de formas cerámicas, sólo aparecían los grabados sobre el revés de platos de barniz rojo, o sobre el cuello o parte superior de la panza de ánforas globulares (fig. 5).

La grafía no es uniforme y lo fragmentario a veces de los nombres impidieron a J. Février demostrar la procedencia de estos recipientes y de sus portadores, aunque se inclinó por pensar que eran de Cartago. ${ }^{23}$

En cuanto a la finalidad de estos textos, este autor suponía que las inscripciones vendrían a afirmar un derecho de propiedad. Las ánforas estarían llenas de pacotilla y serían enviadas desde lejos a Mogador por un comerciante a su correspondiente allí, junto con una carta de viaje. ${ }^{24}$

Nosotros creemos que al ser la práctica de enviar mercancías de un lado a otro francamente común para los comerciantes fenicios, habría que convenir, si aceptamos la hipótesis de J. Février, que es muy extraña la escasez de estos graffiti en los yacimientos tanto fenicios como indígenas del Extremo Occidente que han recibido mercancías. También resulta extraña en la explicación de J. Février, la falta de marcas en otros tipos cerámicos, así como su aparición también en platos que evidentemente no son recipientes de almacenaje.

G. Garbini, no satisfecho con esta hipótesis, llegó a proponer un destino distinto para estos grabados, atribuyéndoles un uso cultual, y sobre la base del material análogo de la isla de Malta, propuso otra cronología, ss. IV-III a.C., para los mismos. ${ }^{25}$

Si G. Garbini entiende, cosa que no sabemos, (falta alguna coma por aquí?, no se entiende) que las inscripciones fueron hechas ya sobre fragmentos cerámicos, a manera de ostraka, resulta sorprendente la aparición de los grabados sólo sobre platos y cuellos de ánforas. Si las inscripciones supuestamente sacras están relacionadas con el continente, platos y ánforas, y tienen carácter de ofrenda, también nos parece extraña esta fijación sobre dos formas, además tan dispares. No nos parece suficiente el carácter teóforo de los nombres, ni el hallazgo de un monolito o betilo de carácter sacro en el yacimiento para aceptar dicha hipótesis.

22 JODIN 1966, 185; FÉVRIER 1966, 109-123.

23 FÉVRIER 1966, 123.

24 FÉvrier 1966, 122-123. Aubet $(1987,255)$ ha hecho suya esta hipótesis, llegando a proponer que Magón, uno de los nombres que aparecen en estos fragmentos de cerámica, era un rico comerciante o naviero gaditano.

25 La nueva cronología propuesta es totalmente descartable, dada la considerable precisión a la que se ha llegado en la datación del yacimiento de Mogador. No he podido leer su artículo en A.I.U.O.N. 28, 1968, 226228, pero el mismo autor recuerda su hipótesis en GARBINI 1986, 70. 
Nuestra propuesta de explicación es en esencia distinta.

Estamos de acuerdo con J. Février que tales graffiti afirmaban un derecho de propiedad. Pero la práctica documentada en Mogador, precisamente por no haberse documentado apenas en otros establecimientos de la zona del Estrecho, creemos que debe explicarse a partir precisamente de lo que distingue al establecimiento de Mogador de todos ellos: su carácter de factoría extrema no consolidada.

Si durante las estancias en Mogador, los fenicios vivían en comunidad y no en unidades familiares, como corresponde a una estación que no se ha convertido en hábitat definitivo destinado a perdurar, es lógico señalar con marcas de reconocimiento, o con el propio nombre, los objetos de uso personal. Así es natural ver estas marcas en los platos que utilizaba cada comensal en el comedor común. Los nombres sobre las ánforas también indicaban quiénes eran sus respectivos propietarios, ya sea como recipientes que contenían el producto para el que fueron fabricadas, o vacías de su contenido para guardar objetos personales, o en todo caso, posibilidad que me parece más aceptable, como recipientes individuales de agua, que cada uno debe administrarse, dado el esfuerzo que supone sin duda el abastecimiento de agua en este paraje.

De esta manera creemos que se explica más fácilmente la abundancia de estos graffiti aquí en Mogador y su rareza en otros establecimientos coloniales fenicios. También explica mejor la selección de sólo dos tipos de recipientes cerámicos, utilizados para uso personal, mientras los otros no se marcan, o bien porque son de uso común, o bien porque están destinados al comercio con los indígenas.

Esta explicación, a partir del carácter excepcional de Mogador, aclara en gran medida las notables dificultades para encontrar paralelos de esta costumbre en otros yacimientos. Con todo, el grabado del nombre como "marca de propiedad para uso" está atestiguado en la Península Ibérica. Con este fin, en el yacimiento indígena de la Peña Negra (Crevillente, Alicante), un fenicio grabó su nombre, BD'SMN, en el envés de un plato de barniz rojo local. En Medellín (Badajoz), en el interior del país, otro fenicio hace lo mismo. Y en el Cabezo de La Esperanza (Huelva) un graffiti sobre la panza de un ánfora de saco con el nombre KRY sería la marca de otro fenicio, según J. de Hoz. También un nombre propio tenemos documentado en un vaso del establecimiento fenicio de Toscanos. ${ }^{26}$

Mogador no llega nunca a sobrepasar el estadio de factoría, pues no se convierte en morada permanente con destino a durar. Durante la mayor parte de su existencia, fue la última factoría sobre el Atlántico Sur, la última "tierra habitada" por los fenicios, la "última Cerné" como en un momento anterior lo debió ser Lixus y probablemente Sala. ${ }^{27}$

Ningún otro establecimiento fenicio de la zona del Estrecho es equiparable. Desde un principio éstos son considerados como hábitat permanente, ya sea como simples escalas marítimas o como colonias "de poblamiento", con una organización administrativa sumamente compleja. ${ }^{28}$

\footnotetext{
26 Sobre estos grafftti véase GonzÁlez Prats 1986, 220; Almagro Gorbea 1977; ID. 1983, 446, n. 112; DE Hoz 1986, 75. Consideran KRY un topónimo Ferron - Fernández Miranda - Garrido 1975.

27 Sobre el carácter móvil del establecimiento de Cerné véase: Ramin 1974; sobre Sala, BouBe 1981; Picard 1982, 167-173. Sobre Lixus, TarRadell 1958; ID. 1959. En último lugar véase, LóPez-Pardo 1991.

28 Aubet 1986a, 27; Bunnens 1986, 191.
} 
Como ejemplos de escalas tenemos entre otros, el islote de Rachgoun en la región de Orán y Ebussus en Ibiza y se desarrollan como colonias la mayoría de los establecimientos fenicios de la costa mediterránea española.

Interpretando las fuentes literarias sólo Sexi (ensayo) y Gadir (práctica) en la zona norte y (probablemente) Lixus en la sur, fueron en un momento dado factorías similares a Mogador. Pero arqueológicamente ninguna de ellas ha mostrado un nivel de esa fase. El gran interés pues de Mogador reside en ser un ejemplo de presencia fenicia no documentado hasta el momento, prototipo-epílogo de "la factoría extrema".

Es de señalar también en este apartado de elementos propios de una factoría primitiva la existencia del monolito de Mogador, que con toda verosimilitud señala la existencia de un lugar de culto en el centro del yacimiento, donde apareció. Ello nos documenta arqueológicamente la costumbre fenicia de erigir un ara o recinto sagrado desde el momento que ponen pie a tierra. Práctica ya percibida en otros lugares que demuestran la estrecha vinculación de alguna o algunas divinidades fenicias con la empresa comercial. En este sentido es especialmente ilustrativo que las fechas de fundación de Gadir y Utica se refieran a sus respectivos santuarios y no al surgimiento de sus colonias. ${ }^{29}$

Si bien a J. Février le había parecido probable que los comerciantes en Mogador venían de Cartago, por su parte A. Jodin señalaba la procedencia o similitud de los materiales de Mogador de y con el Mediterráneo Oriental tanto en Grecia como en Chipre o la costa fenicia. También encontraba paralelos en Rachgoun (Oranesado) y sobre todo en los establecimientos del Extremo Occidente. ${ }^{30}$

La aparición de algunos elementos muy específicos señalan una especial relación con la Península Ibérica, como el fragmento de cerámica de retícula bruñida, las ánforas de tipo "Cruz del Negro", los trípodes, etc. ${ }^{31}$

La evidencia de esta vinculación ha ido acrecentándose paulatinamente. La publicación de los materiales de Toscanos ha venido a demostrar que no sólo los materiales propiamente fenicios son similares, sino también en lo referido a la importación de otros objetos del Mediterráneo Oriental. En Toscanos, al igual que en Mogador, se han hallado ánforas SOS áticas y ánforas de Quíos, además de productos chipriotas. ${ }^{32}$

A pesar de esta similitud entre Toscanos y Mogador, no existe una identidad absoluta en algunas formas cerámicas ni en sus decoraciones, especialmente en las piezas fenicias pintadas, así como en la distinta proporción de hallazgo de los tipos. Diferencias que también han sido señaladas entre Toscanos y los yacimientos indígenas de la Península Ibérica que recibieron importaciones fenicias. Ello parece explicarse en Toscanos por el carácter de colonia del hábitat.

Mogador parecía pues vincularse al establecimiento más dinámico en la empresa comercial, Gadir. Tal suposición hubiera quedado en el estado de hipótesis, si no fuera por los recientes descubrimientos del próximo yacimiento de Castillo de Doña Blanca en la bahía de Cádiz.

\footnotetext{
29 Bunnens 1979, 186. Sobre el papel de los templos en la empresa comercial fenicia véase también: ACQuaro 1988; Aubet 1987, 136-137.

30 FÉVRIER 1966, 123; JodIN 1966, passim.

31 Aubet 1987, 115-116.

32 Vide supra.
} 
Éste es un establecimiento que surge en la primera mitad del s. VIII a.C., a partir del intercambio de productos entre indígenas y fenicios, donde en un principio la población debió ser fundamentalmente indígena a juzgar por la gran cantidad hallada de cerámica a mano del Bronce Final. Sus relaciones de dependencia respecto de Gadir son sin embargo una incógnita. Para nuestro propósito lo más significativo es que su cerámica a torno procede de la ciudad fenicia.

Su gran interés reside en que lo que entre los materiales de Toscanos y Mogador es similitud, entre Castillo de Doña Blanca y Mogador es identidad. Tanto es así que D. Ruiz Mata, tras excavar el yacimiento de la bahía de Cádiz, llega a afirmar que Mogador depende "absolutamente" de Gadir. ${ }^{33}$

Si bien es posible afirmar de forma categórica que la factoría de Mogador pertenece a una empresa comercial centrada en el Extremo Occidente que parece tener por eje Gadir-Lixus-Mogador, descartando cualquier vinculación directa con el Mediterráneo Central, es difícil establecer cómo se organiza esta dependencia. Sospechamos, sin embargo, que Mogador depende de una estructura comercial y no de una o varias colonias, con participantes en Lixus, en Gadir, e incluso en la metrópoli oriental, en Tiro.

Los materiales de Mogador indicarían que es en Gadir donde se ha reunido la mayoría de ellos, tanto los producidos en Fenicia, Chipre, Quíos, y el Ática, como los fabricados en Gadir o sus proximidades, (la cerámica indígena de retícula bruñida, y seguramente los platos y fuentes de barniz rojo, jarros, etc. que empiezan a hacerse allí con vistas a abaratar costes. La participación de Lixus, sin duda importante, queda sin embargo por explicitar a partir de nuevas excavaciones.

\section{Mogador y la cuestión del comercio fenicio en la costa atlántica africana}

Desde el mismo descubrimiento de los niveles fenicios de Mogador, fue expuesta su posible identificación con la isla de Cerné. Precisamente en la Cerné descrita en él periplo de Escílax la práctica de los fenicios de cobijarse en tiendas parecía corresponder con Mogador, por la falta de estructuras constructivas allí detectada. ${ }^{34}$

Profusamente citada en fuentes literarias, Cerné era considerada como el último lugar habitado conocido, y por ello tuvo un emplazamiento cambiante y en un momento dado debió ser sin duda Mogador, donde varios indicios señalan que fue por un tiempo la última factoría fenicia. ${ }^{35}$

Esta Cerné, interpretando el relato del Periplo de Escílax, es la isla donde los fenicios desembarcan sus mercancías, especie de factoría almacén, para después desplazarse a tierra firme y allí comerciar con los etíopes, los cuales les ofrecen pieles de animales salvajes y domésticos y menciona entre ellos a ciervos, leones, leopardos

33 Ruiz Mata 1986, 260.

34 Señalaron esta relación: Jodin 1966, 187; DeSANGes 1978, 52-53; ID. 1978a, 117-119; Ramin 1974, 442.

35 Sobre ello véase: Ramin 1974. Después, desde mediados del s. VI a.C. hasta el s. I a.C., Mogador fue una escala ocasional como atestiguan el hallazgo de un ánfora Mañá-Pascual 44, datable entre finales del s. VI y s. III a.C., y huesos de elefante (JodIN 1966, 187). 
y elefantes. Además los fenicios obtienen marfil, muy abundante y frecuentemente utilizado por los indígenas. A cambio, los comerciantes les traen ungüentos, piedra de Egipto, cerámica ática y jarras para vino. ${ }^{36}$

El relato parece ser bastante verosímil y nada impide aceptar que estas mercancías, pieles de animales y marfil fueran tradicionalmente buscadas y obtenidas por los fenicios, y que fueran éstas las que motivaron que estos comerciantes navegaran hacia el sur. ${ }^{37}$

Exceptuando el texto del Periplo de Escílax, ningún testimonio prerromano confirmaba la comercialización del marfil marroquí.

Sólo había sido documentada la existencia de talleres trabajando el marfil en la zona de Cádiz, marfil que a veces había sido comercializado muy lejos. ${ }^{38}$ La cantidad de productos salidos de estos talleres indicaban una fluida fuente de aprovisionamiento, que sugería que este marfil procedía de elefantes norteafricanos, y no de la India o del Cuerno de África.

Por su parte, en el Marruecos atlántico tanto las fuentes literarias como los restos arqueológicos indican la caza frecuente de elefantes en época romana. Sólo el hallazgo de huesos de paquidermo en la isla de Mogador y en las marismas del Tahadart (Tánger) indicaba el consumo de su carne en época prerromana. ${ }^{39}$

Creemos que un reciente e importante hallazgo puede ser aducido sobre la obtención y comercio del marfil en la costa atlántica marroquí. Se trata del pecio del Bajo de la Campana, junto al Mar Menor (Murcia), donde se han sacado trece defensas de gran tamaño de elefante africano (fig. 6). ${ }^{40}$

Según nuestra opinión los diferentes elementos de la carga que acompañaban al marfil nos demuestran dicho origen marroquí. Un ánfora ovoide fenicio-púnica, así

36 A pesar de que el término chous puede tener un significado genérico de jarra, aquí sin duda tiene el sentido específico y más frecuente de "jarra para vino", ya que a continuación, en el Periplo de Escílax se afirma que los vasos áticos y los choes se venden en la fiesta de los Choes: Periplo de Escílax 112 (G.G.M., 94). Sin duda se trata de la fiesta de las Anthesterias de Atenas, y no de una fiesta etíope similar. En dicha fiesta el segundo día recibía el nombre de Choes, día en que se utilizaba esta jarra para beber abundante vino. El día anterior, Pithoigia, cuando se abrían los pithoi conteniendo vino, en la ciudad se celebrada un mercado donde se podía comprar el vino nuevo traído del campo y las jarras y demás utensilios para los días de Choes y Chytres. Choes a veces da nombre a toda la fiesta y es seguramente en esta acepción con que la utiliza el autor del Periplo de Escílax pues menciona la venta de cerámica en la fiesta de Choes cuando dicha venta se hace el día anterior (Pithoigia). Sobre el chous y esta fiesta véase: DAREMBERG - SAGLio 1969, s.v. "Dionisias", 237. En nuestra opinión, esta referencia a las fiestas de las Anthesterias o Choes pretende darnos a entender que estos vasos se venden entre los etíopes para beber vino. No sabemos, sin embargo, si este vino es traído por los fenicios o si es producido por los indígenas. En principio nos parece más probable que sea importado, pues con grandes dificultades es posible caracterizar a los etíopes como productores de vino, a pesar de que en el Periplo de Escílax se nos diga que ellos producen mucho vino de sus viñas, que los fenicios exportan. Esta afirmación entra en flagrante contradicción con lo que dice inmediatamente antes, que los etíopes comen carne y beben leche, lo cual los define como un pueblo eminentemente pastoril; DESANGES (1978a, 117) no acepta que los etíopes fueran productores de vino.

37 A estos productos habría que añadir las cáscaras de huevos de avestruz, que se han encontrado en los niveles de Mogador, en Lixus, Banasa, en las necrópolis de Tánger y en algunos establecimientos fenicios de la Península Ibérica al menos desde el s. VII a.C. (CInTAs 1954, 54; Ponsich 1967, passim).

38 Aubet 1979.

39 Str. XVII, 3, 4 y 7; Plin. Nat. Hist. XVIII, 5, 5; JodIN 1970, 64.

40 Mas 1985; RAmón 1986. Con este preciso estudio de un tipo de ánfora de los siglos VII y VI a.C., J. Ramón llega a deducir claramente que se han mezclado dos pecios de épocas distintas, uno arcaico y otro del siglo II a.C., lo cual altera la cronología inicialmente propuesta tras el descubrimiento. 


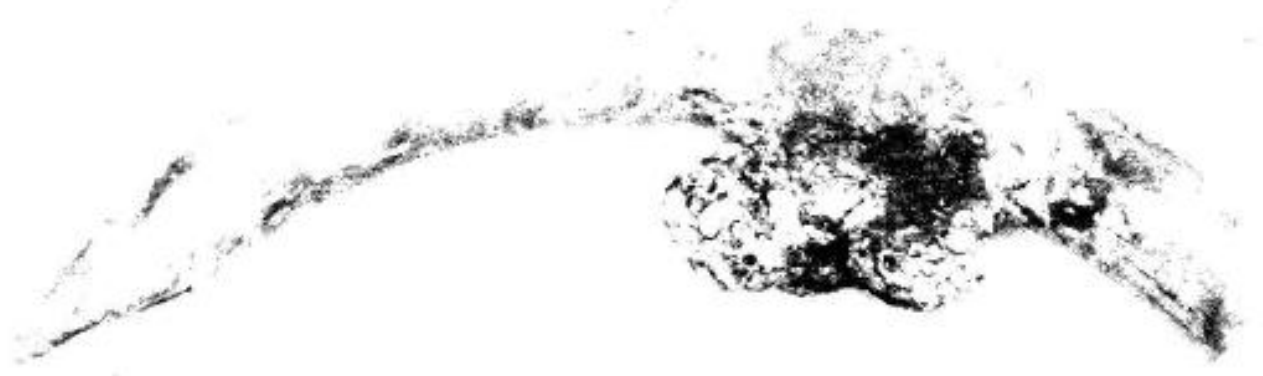

Fig. 6. Defensa de elefante con lingotes de estaño adheridos, hallada en el pecio del Bajo de la Campana (según J. Mas, "El polígono submarino de Cabo de Palos. Sus aportaciones al estudio del tráfico marítimo antiguo", VI Congreso Internacional de Arqueología Submarina. Cartagena, 1982, Madrid, 1985, 161, lám. II, 1).

como un trípode y platos o morteros con el mismo perfil que los trípodes de Riotinto. Lingotes de estaño en forma de casquete esférico y lingotes de plomo, fusiformes. Mezcladas con ellos, ánforas troncobicónicas, Mañá E, procedentes sin duda de otro barco más moderno. El fósil director que data el conjunto son precisamente el ánfora y los platos, datables del s. VII y VI a.C. (fig. 7).

La procedencia de los diferentes elementos marca claramente el recorrido del barco. Los productos manufacturados indican que se trata de un puerto fenicio occidental y los lingotes de plomo y especialmente los de estaño señalan claramente un puerto atlántico. El estaño podía ser obtenido casi exclusivamente en la fachada atlántica peninsular o más al norte. Al extremo es posible que llegara a manos de los fenicios por un camino terrestre hasta el valle del Guadalquivir. ${ }^{41}$

Todo ello nos conduce inevitablemente a creer que el marfil procede de la costa atlántica africana. La confluencia del estaño y el marfil además señala Gadir como punto de embarque verosímil de la mayoría de las mercancías.

Este hallazgo del pecio del Bajo de la Campana nos ilustra no sólo sobre el comercio de marfil marroquí, sino también de algunas prácticas comerciales. En algunas de las defensas se han conservado inscripciones, de las cuales, cuatro son más amplias y están completas. Según J. Sanmartín Ascaso, se componen de una fórmula de cortesía, "tu servidor" o "humildemente" y después un nombre. Los caracteres son fenicios, tirio-sidonios, no púnicos. La ausencia de toda indicación dativa, señala, más que a un destinatario, a una marca de propiedad del remitente (fig. 8). ${ }^{42}$

En nuestra opinión, estos graffiti en realidad no tienen nada que ver con el viaje emprendido por el barco del pecio del Bajo de la Campana, pues no tiene sentido marcar las defensas para la venta en un ambiente que no era fenicio-occidental, quizá ni siquiera púnico, con un nombre de remitente.

41 Alvar Ezquerra 1983, 43; Álvarez Rojas - Gil Montes 1988.

42 Sanmartín Ascaso 1986. 

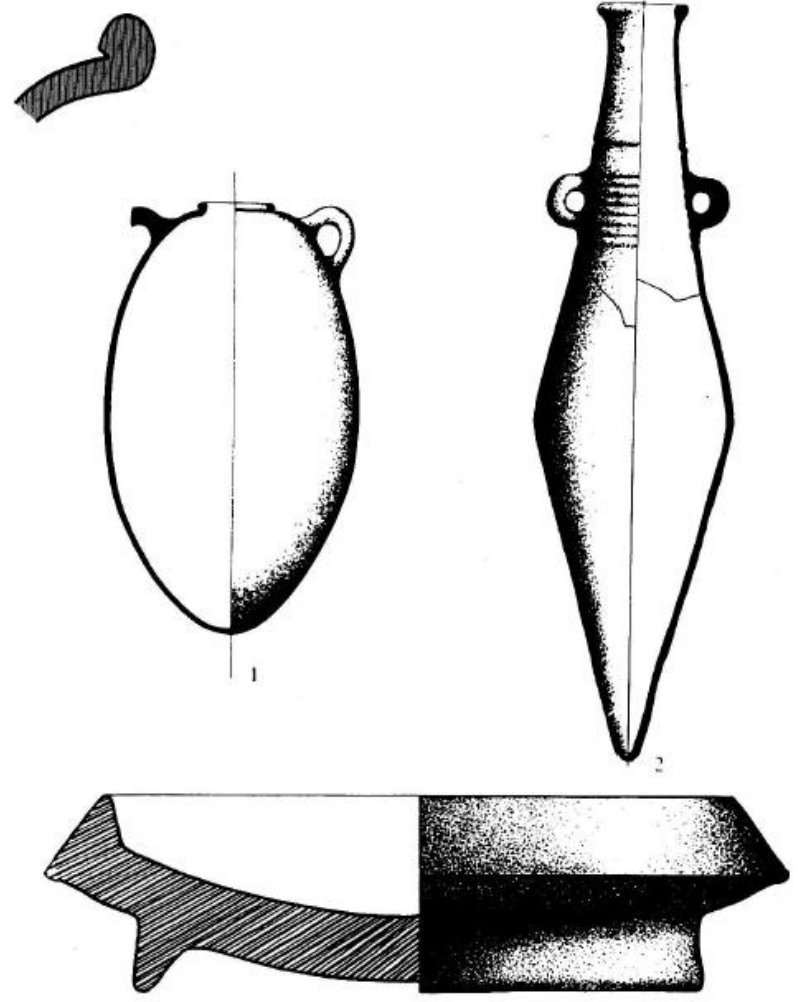

Fig. 7. Materiales cerámicos del Bajo de la Campana (según J. Mas, "El polígono submarino...", 157, fig. 3).

Las defensas fueron marcadas para otro viaje anterior. El efectuado desde donde se encuentra el agente comercial fenicio, en el medio indígena, y su jefe o sede de empresa comercial, ya sea en Gadir, o quizás en Lixus. De esta manera quedará registrado en las cuentas quién ha obtenido cada pieza, que mezcladas en el primer viaje no podrán ser confundidas.

Estos proveedores, desplazados a la tierra ignota, el escalón más bajo y peligroso de la empresa comercial, se preocuparán individualmente por obtener el marfil, que enviado a la sede central, les permitirá obtener un beneficio porcentual y acumular así un pequeño capital y ascender con él y su "espíritu emprendedor" en la empresa, estructurada seguramente con lazos familiares. Ello explica que desde el primer momento el marfil sea marcado con un nombre, el del proveedor. ${ }^{43}$

43 No tenemos apenas información sobre la estructura del comercio fenicio del Ier milenio, por ello la información de estos graffiti es especialmente valiosa. 


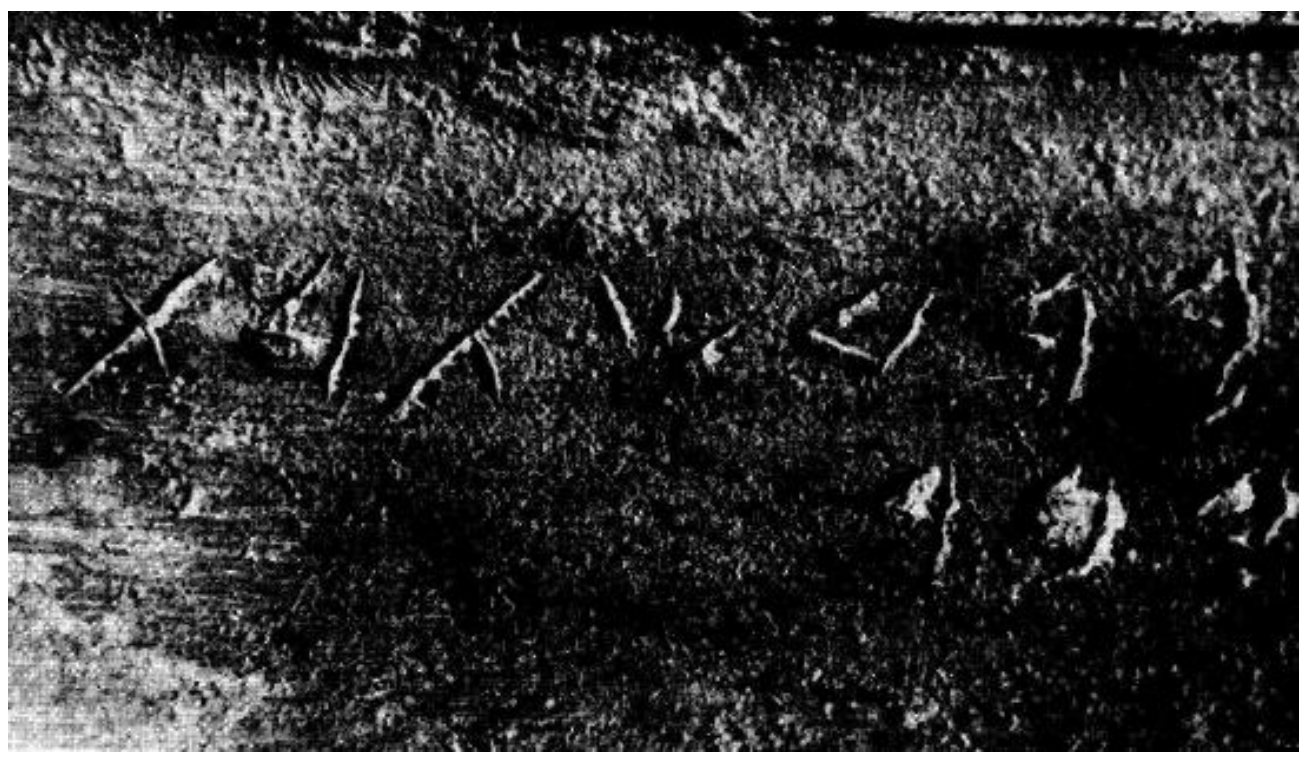

Fig. 8. Inscripción sobre defensa de elefante del Bajo de la Campana (según J. Sanmartín Ascaso, "Inscripciones fenicio-púnicas del Sureste hispánico. (I)", Los Fenicios en la Península Ibérica, Sabadell, 1986, 97, foto 2).

Pero ¿realmente el marfil, los huevos de avestruz y las pieles de animales justifican el descendimiento de los fenicios tan al sur, hasta Mogador y seguramente más allá? ${ }^{44}$

Un famoso texto de Herodoto sobre el comercio a la muda realizado en la "Libia" atlántica nos señala que los cartagineses (seguramente es una confusión del autor y se trata de fenicios) obtienen oro de los indígenas. ${ }^{45}$

Otro texto, muy difícil de utilizar, oscuro y con pocas garantías de verosimilitud, señala también esta riqueza de oro. En un resumen, quizás muy tardío, de una obra de un supuesto discípulo de Aristóteles llamado Palaiphatos, se menciona la enorme riqueza de los habitantes de Cerné, y más adelante se afirma que su rey, Phorcys, hizo esculpir una estatua de oro de Atenea. ${ }^{46}$

Estos textos y la obtención de oro atestiguada ya en la Edad Media en la cuenca del río Níger, en la región del Bámbuk, permitieron a Jerôme Carcopino construir una bella hipótesis sobre un comercio del oro de gran alcance, desarrollado por los fenicios y cartagineses a lo largo de la costa africana. Por desgracia, la persistente falta de datos impide por el momento contrastar claramente esta hipótesis.

44 No hay evidencia de que la obtención de madera de tuya y cedro esté incluida en la explotación fenicia. Se sabe que es extraída en época de Iuba II al menos.

45 Hdt. IV, 196.

46 Palaiphatos, 31. El texto es valorado por CARcopino (1943, 117-118) y Desanges (1978, 52). Quizá en este relato se produce la misma confusión que en Avieno, entre Tartessos y Gadir, la estación fenicia de Cerné es tomada por el reino indígena del oro. 
En este sentido, el camino seguido por Jehan Desanges para evitar esta laguna ha sido ingenioso, ha consistido en intentar averiguar cuál pudo ser la repercusión del oro africano atlántico sobre los recursos de este metal en Cartago, supuestamente la principal receptora del mismo.

Llegó a la conclusión de que la repercusión debió ser mínima, y que el escaso oro reunido por fenicios y cartagineses en esta costa pudo haberse adquirido no más allá del valle del Sous. No sabe si a través de un comercio transahariano de poca envergadura, o por la existencia de minas de oro en el Atlas. ${ }^{47}$

En este interesante supuesto, en el valle del Sous se localizaría el mercado indígena adonde llegaba el oro y Mogador sería la "factoría extrema" que albergaba a los comerciantes fenicios y sus mercancías. No sería sólo como la Cerné del Periplo de Escílax donde se acumulan huevos de avestruz, marfil y pieles de animales, sino también como la Cerné desfigurada de Palaiphatos, rica en oro.

A pesar de todo lo expuesto, nada por el momento nos ilustra sobre la verdad de este comercio áureo ni de su procedencia.

En el Marruecos atlántico ningún vestigio ni noticia hasta el presente existe sobre una posible explotación de oro. B. Rosenberger entiende que la producción de oro en Marruecos, ha sido insignificante, cuando no inexistente. Las referencias medievales o posteriores, a la obtención del oro, según el autor, así lo indicarían. ${ }^{48}$

Por otro lado, tanto T. F. Ganard como Danilo Grebenart niegan el comercio del oro del África subsahariana hacia el norte y consideran también improbable la explotación del oro con anterioridad al Bajo Imperio. Según D. Grebenart el oro está misteriosamente ausente de los yacimientos del Sahel antes de la Edad Media. ${ }^{49}$

Ningún texto menciona otros metales por los cuales pudieran estar interesados los fenicios en esta zona.

A lo largo de la historia, el estaño es un metal que ha faltado en Marruecos. B. Rosenberger en su documentado estudio sobre las viejas explotaciones mineras de Marruecos, señala sólo un hallazgo en todo el país, Oulmes-El Karite. Su resonante descubrimiento se produjo en el año 1638. Ningún autor menciona ninguna explotación anterior a esta fecha en todo el país. Es probable sin embargo que fuera explotado con anterioridad, pues se han encontrado en el lugar monedas de época almohade o puede que merinidas. ${ }^{50}$

47 Carcopino 1966, 73-163; Desanges 1978, passim.

48 Rosenberger 1970, 83-84.

49 Garrard 1982; Grebenart 1988, 108. Una situación similar nos encontramos con el comercio de la plata. Existe un coto minero en la Addana, al interior de Marruecos, entre el uadi Noun y el Draa. Las referencias más antiguas de Yahoubi y El Bekri, s. IX y XI respectivamente, mencionan una montaña de plata aquí, y la construcción de una ciudad fortificada por el nieto de Idriss. El lugar es conocido con el nombre de Tándoult. La galena argentífera es de unos $50 \mathrm{~cm}$ de espesor y de una pureza de $1200 \mathrm{~g}$ de plata por tonelada (RoSENBERGER 1970, 79-81). Aunque nada indica que fuera explorada en época preislámica, cerca de allí, en el paso del Yebel Beni, que da acceso a esta zona, se encuentra el "agadir" de Foumm el Hassane, construcción que hace las veces de fortaleza y granero colectivo construido por los Fniks, conocido como Agalir m Fniks, que da la impresión de conservar el nombre de los fenicios. El investigador Jousef Bokbot, me ha señalado amablemente este dato en la obra de JACQUES-MEUNIÉ $(1982,164)$. Por otro lado no hay vestigio alguno del comercio transahariano de la plata. Ningún objeto de plata se ha encontrado en el Sahara ni en el Sahel anterior al s. V d.C. (GreBEnART 1988, lám. 148).

50 Rosenberger $(1970,99)$ dice: “On a trouvé dans les déblais des lampes de céramique, qu'on a un peu vite, peut-être, qualifiées de "romaines"”. 
La permanencia de una metalurgia de cobre puro en Akjoujt (Mauritania), a lo largo del primer milenio, sin la inclusión de estaño en sus producciones tardías, así como la escasez de objetos de bronce en Marruecos y su más que probable origen foráneo, invitan a pensar que el estaño no se obtenía en el país, y que no se importaba, al menos en cantidades considerables, para ser aleado al cobre.

Si la fabricación de objetos de cobre no está tampoco documentada literariamente en época prerromana los restos arqueológicos indican que había una metalurgia autóctona del cobre a partir del mineral no nativo, como mínimo desde el II milenio a.C. ${ }^{51}$

El hallazgo de explotaciones mineras de cobre en Akjoujt, en Mauritania ya a finales del II milenio hasta finales del I, indica claramente esta existencia previa. Pero también la distribución de hallazgos de este metal y su escasez en Mauritania y Marruecos nos señala el carácter excepcional de esta producción. En Mauritania los objetos de cobre protohistóricos encontrados son más que en Marruecos, 140 objetos, pero también es destacable su escaso número en términos absolutos. Hemos de señalar sin embargo su gran concentración en torno a Akjoujt, de cuyo entorno proceden 127 del total, y por otro, el hecho de que sean de cobre casi puro, a pesar de la perduración de la explotación minera hasta el s. II a.C. ${ }^{52}$

No existe indicio alguno de la producción de bronce fuera de la presencia fenicia.

De los muy escasos hallazgos, uno es una espada procedente del estuario del Lukkos, cuyos paralelos tipológicos se encuentran al norte del valle del Loira, es una pieza sin duda importada. ${ }^{53}$

También parece venir de fuera la punta de flecha de la necrópolis Ain Dalhia Kebira, y la hoja de puñal o alabarda de la de Mers, ambas en la región de Tánger. ${ }^{54}$ Esta última pieza, tanto por el tipo de enmangue y por el engrosamiento central parece un producto subargárico procedente del sur de la Península Ibérica.

Un asa de bronce arsenical hallada en la necrópolis de Tayadirt en el Tafilalt es una pieza púnica. ${ }^{55}$ Los otros dos hallazgos publicados son dos hachas de bronce sin

51 Es probable incluso que pueda remontarse al III milenio. Unos útiles de cobre hallados en la gruta de Kef el Baroud, en la región de Ben Slimane (zona de Casablanca) pueden estar asociados a materiales cerámicos datados por $\mathrm{C} 14$ entre el 3210 +/- 110 y 2800 +/- 110 a.C. Sin embargo, el dato no es seguro, pues de dichos objetos, uno apareció en superficie, y los otros dos antes de la excavación científica, sin poder asociarlos estrictamente a las muestras para la datación con C14. Sobre el yacimiento de Kef et Baroud y la problemática de sus objetos de cobre véase: WAILLY 1973-1975, 39-101; ID. 1976, 47-51. Desgraciadamente en la excavación sistemática no apareció ningún objeto metálico. Otro hallazgo, esta vez en el Alto Atlas, en el yacimiento de La Caze, Oukaimeden, es muy inseguro. J. Malhomme en carta dirigida a G. Camps da a conocer el hallazgo de tres objetos de cobre en conexión con una industria de silex (CAMPS 1961, 229, n. 5). Esta industria metalúrgica de cobre se difunde por el Marruecos atlántico y Mauritania, y, según la opinión más generalizada, a partir del sur de la Península Ibérica. Precisamente en la costa atlántica marroquí se documenta la extensión de culturas, o elementos culturales, que normalmente aparecen asociados en el sur de la Península Ibérica a la metalurgia del cobre. Así puede verse el reparto a lo largo de la costa hasta Casablanca, de vasos campaniformes. A este respecto véase: Souville 1986; ID. 1988, 291-292; OnRUBIA Pintado 1988, 162; Grebenart 1988, 59.

52 Véase Grebenart 1988, 131-132.

53 Ruiz-Gálvez Priego 1983.

54 Ponsich 1970, 51 y 57.

55 A este respecto véase: LAMBERT 1967; LAMBERT - Souville 1969-70; ID. 1970. 
contexto conocido, hallados próximos a la costa, uno en la zona de Rabat, y otro en la zona de Uxda. ${ }^{56}$

No obstante, en el interior del Gran Atlas son figurados en sus grabados rupestres muchos objetos de cobre o bronce, aunque con datación imprecisa, son indicio del trabajo artesanal del cobre o bronce en época protohistórica en estas zonas. ${ }^{57}$

Por lo que venimos apreciando, si bien queda constatada la existencia de la metalurgia del cobre, y sólo de esta, por ahora, antes de la presencia fenicia, la escasez de hallazgos en Marruecos, su concentración en torno a Akjoujt, en una veta metalífera pobre, en Mauritania, sin hallazgos más al sur, donde permanece una cultura con útiles de piedra pulida, nos impide considerar que el cobre o el estaño fueran mercancías obtenidas por los fenicios en estas latitudes. Sólo por el momento pueden ser tenidos en cuenta las pieles de animales, los huevos de avestruz, y especialmente el marfil, y quizás el oro, como los recursos captados por los gaditanos y lixitas en esta costa, donde Mogador fue alguna vez su "factoría extrema".

\section{Intervention et réponses}

\section{MOREL}

En entendant le riche exposé de M. López Pardo sur Mogador, j'ai plus d'une fois pensé aux problèmes analogues que nous pose une autre colonisation venue de l'Orient jusqu'au lointain Occident, celle des Phocéens et d'autres Ioniens: mêmes comptoirs communautaires, par exemple à Gravisca (ou encore à Naucratis); même hésitation, de notre part à décider ce qui appartient, dans les comptoirs, á la métropole orientale ou á ses grandes colonies occidentales (ici, Tyr ou Carthage; là, Phocée ou Marseille, par exemple à Ampurias). Il est clair que "ce caractère extrême et non fixé", pour reprendre les termes de F. López Pardo, suscite pour ainsi dire les graffiti-nombreux à Mogador, nous a-t-il dit- aussi bien comme une façon pour chacun de revendiquer ce qui lui appartient dans une communauté mouvante que comme une affirmation des "Méditerranéens" face aux "indigénes": voir Gravisca. Ces établissements, lointains, isolés, menacés, appellent aussi, fréquemment, la présence d'un sanctuaire valant garantie, protection, asile: voir Naucratis, voir Héra à Gravisca, voir Melqart à $G a$ dir et à Lixus. A-t-on recueilli à Mogador quelque indication pouvant faire penser d l'existence d'un sanctuaire?

\section{$\underline{\text { LÓPEZ PARDO }}$}

À part le monolithe déjà mentionné, aucun élément appartenant au sanctuaire de Mogador n'a été trouvé. De toute façon, on doit admettre l'existence d'un sanctuaire à Mogador, en raison de la coutume phénicienne d'instaurer un lieu sacré, là où les commerçants débarquent, une coutume qui est solidement attestée.

56 Grot - Souville 1964; Souville 1964.

57 Véase Jodin 1966 a. 


\section{CAMPS}

Je voudrais savoir si, en dehors des lingots d'étain, l'épave du Bajo de la Campana renfermait d'autres éléments d'origine nordique. En fait, pourquoi cet étain ne viendrait-il pas, lui aussi, du Maroc? Le gisement d'Oulmès a pu être exploité dés l'Antiquité.

\section{LÓPEZ PARDO}

L'existence d'une production d'étain au Maroc dans l'Antiquité n'est pas attestée. Le fait que très peu d'objets de bronze ont été travaillés dans le pays montre que les Phéniciens ne pouvaient être attirés par une hypothétique production.

\section{Bibliografía}

Acquaro, E. (1988): "Il tempio nella precolonizzacione fenicia", [en] E. Acquaro et alii, Momenti precoloniali nel Mediterraneo antico, Roma, 187-189.

Almagro Gorbea, M.

(1977): El bronce final y el periodo orientalizante en Extremadura, Madrid.

(1983): "Colonizzazione e aculturazione nella Peninsola Iberica", [en] Modes de contacts et processus de transformation dans les sociétés anciennes, Pisa-Roma, 429-461.

Alvar Ezquerra, J. (1983): "EI comercio del estaño atlántico durante el período orientalizante", Memorias de Historia Antigua 4, 43-50.

Álvarez Rojas, A. - Gil Montes, J. (1988): “Aproximación al estudio de las vías de comunicación en el primer milenio antes de Cristo en Extremadura", TP 45, 305316.

Aranegui, C. (1980): "Contribución al estudio de las urnas de tipo Cruz del Negro", Saguntum 15, 99-118.

Aubet, M. E.

(1979): "Marfiles fenicios del Bajo Guadalquivir. I: Cruz del Negro", Studia Archaeologica 52, 18-33.

(1986): "Contactos culturales entre el Bajo Guadalquivir y el Noroeste de África durante los siglos VII y VI a.C.", [en] Atti del Congresso Internazionale "Gli interscambi culturali e socio-economici fra l'Africa Settentrionale e l'Europa Mediterranea", Napoli, 109-144.

(1986): "Los fenicios en España: estado de la cuestión y perspectivas", [en] Los fenicios en la Península Ibérica, Sabadell, 9-38.

(1987): Tiro y las colonias fenicias de Occidente, Barcelona.

BisI, A. M. (1968): “Aspetti e problemi de la cerámica punica arcaico dipinta”, Studi Maghrebini 1, 9-16.

Boube, I. (1981): "Les origines phéniciennes de Sala de Maurétanie", BCTH 17, B, 155-170. 
BunNENS, C.

(1979): L'expansion phénicienne en Méditerranée, Bruxelles-Rome.

(1986): "Le rôle de Gadès dans l'implantation phénicienne en Espagne", Aula Orientalis 4, 187-192.

Camps, G. (1961): Aux origines de la Berbérie. Monuments et rites funéraires protohistoriques, Paris.

CArcopino, J. (1943): Le Maroc antique, Paris.

CinTAS, P.

(1954): Contribution à l'étude de l'expansion carthaginoise au Maroc, París. (1970): Manuel d'Archéologie punique, Paris.

Daremberg, Ch. - Saglio, E. (1969): Dictionnaire des Antiquités grecques et romaines, Graz.

De Hoz, J. (1986): "Escritura fenicia y escrituras hispánicas. Algunos aspectos de su relación", [en] Los fenicios en la Península Ibérica, Sabadell, 73-84.

De Wailly, A.

(1973-1975): "Le site du Kef el Baroud (région de Ben Slimane)", BAM 9, 39-101. (1976): "Le Kef-el-Baroud et l'ancienneté de l'introduction du cuivre au Maroc", BAM 10, 47-51.

Desanges, J.

(1978): "Remarques critiques sur l'hypothèse d'une importation de l'or africain dans le monde phénico-punique", [en] Actes du deuxième Congrès International d'Etude des Cultures de la Méditerranée Occidentale 2, Alger, 52-58.

(1978a): Recherches sur l'activité des Méditerranéens aux confins de l'Afrique (VIe siècle avant J.-C.-IVe siècle aprés J.-C.), Rome.

Desjacques, J. - Koeberle, P. (1955): “Mogador et les iles Purpuraires", Hespéris 42, 199-203.

Ferron, J. - Fernández Miranda, M. - Garrido, J.P. (1975): "Inscripción fenicia procedente del Cabezo de la Esperanza", TP 32, 199-211.

FÉVRIER, J. (1966): “Inscriptions puniques et néopuniques”, [en] J. Février, Inscriptions antiques du Maroc, París, 81-132.

GarbinI, G. (1986): Venti anni di epígrafia punica nel Magreb (1965-1985), (=Suppl. RSF 14), Pisa.

GARRARD, T. F. (1982): "Myth and Metrology: The early Trans-Saharian Gold Trade", The Journal of African History 23, 443-461.

González Prats, A. (1986): Estudio arqueológico del poblamiento antiguo de la Sierra de Crevillente (Alicante), Alcoy.

Grebenart, D. (1988): Les premiers métallurgistes en Afrique Occidentale, París.

Grot, P. R. - Souville, G. (1964): "La hache en bronze de l'oued Akrech (Maroc)", Libyca 12, 301-306.

JACQUes-Meunié, D. (1982): Le Maroc saharien des origines á 1670, París. 
JoDIN, A.

(1957): “Recherche archéologique a Mogador, mai-juin 1956”, Hespéris, 363-366. (1957a): "Note relative aux fouilles exécutées à Mogador en mai et juin 1956",BCTH, 118-126.

(1957b): "Note préliminaire sur l'établissemónt pré-romain de Mogador (campagnes 1956-1957)", BAM 2, 940.

(1966): Mogador, comptoir phénicien du Maroc atlantique, Tanger.

(1966a): "Les gisements de cuivre du Maroc et l'archéologie des métaux (gravures rupestres et tumulus)", $B A M 6,11-27$.

(1967): Les établissements du roi Juba II aux îles Purpuraires (Mogador), Tánger. (1970): "L'éléphant dans le Maroc Antique", [en] Actes du 92e Congrès national des Sociétés savantes, 1967, section d'archéologie, Paris, 51-64.

(1978): “Carthage et le Maroc phénicien”, BAM 11, 65-78.

LAMBERT, N. (1967): “Tayadirt. Une nécropole protohistorique en Haute moulouya”, Libyca 15, 215-260.

LAMBert, N. - SOUvilLe, G.

(1969-1970): "Análisis espectrográficos de asas de jarras de bronce de Ampurias, Enserine y Tayadirt (Marruecos)", Ampurias 31-32, 307-310.

(1970): "Influences orientales dans la nécropole mégalithique de Tayadirt (Maroc)", Ant. Afr. 4, 63-74.

López PARdo, F. (1991): "Reflexiones sobre el origen de Lixus y su delubrum Herculis en el contexto de la empresa comercial fenicia", [en] Lixus, Roma, 85-101.

Mas, J. (1985): "El polígono submarino de Cabo de Palos. Sus aportaciones al estudio del tráfico marítimo antiguo", [en] VI Congreso Internacional de Arqueología Submarina, Madrid, 156-159.

Moscati, S. (1988): "La statuaria”, [en] I Fenici, Milano, 284-291.

Muñoz, A. - Berriatua, N. (1988): “Contribución a los orígenes de la industria pesquera y conservera gaditana a través de las recientes aportaciones de la factoría de salazones de la bahía de Cádiz", [en] Actas del Congreso Internacional "El Estrecho de Gibraltar" 1, Madrid, 504-507.

Niemeyer, H. G. (1983): "Una ánfora chiota procedente de Toscanos", [en] Homenaje a M. Almagro Basch 2, Madrid, 253-258.

Niemeyer, H. G. - Schubart, H. (1969): Toscanos, 1964, Berlin.

OnRubia Pintado, C. (1988): "Modalidades, implicaciones y significación de las relaciones prehistóricas ibero-magrebíes. Problemas y perspectivas", [en] Actas del Congreso Internacional "EI Estrecho de Gibraltar" 1, Madrid, 141-171.

PemÁn, C. (1955): "Sobre cronología púnica occidental", AEspA 28, 288-289.

PicARD, C. (1982): "Les navigations de Carthage vers l'Ouest", [en] H. G. Niemeyer (ed.), Phönizier im Westen (=Madrider Beitraige 8), Mayence, 167-173. 
Ponsich, M.

(1967): Nécropoles phéniciennes de la région de Tanger, Rabat.

(1970): Recherches archéologiques á Tanger et dans sa région, Paris.

Quillard, P. (1979): Bijoux carthaginois. I. Les colliers d'après les collections du musée national du Bardo et du Musée National de Carthage, Leuven.

Ramin, J. (1974): “Ultima Cerne”, Mélanges R. Dion, París, 439-449.

RAMÓN, J.

(1982): "Cuestiones de comercio arcaico. Frascos fenicios de aceite perfumado en el Mediterráneo Central y Occidental”, Ampurias 44, 35-36.

(1986): "Exportación en Occidente de un tipo ovoide de ánfora fenicio-púnica de época arcaica", Cuadernos de Prehistoria y Arqueología Castellonenses 12, 97-122.

Rosemberger, B. (1970): "Les vieilles exploitations minières et les centres métallurgiques du Maroc, essai de carte historique, II”, Revue de Géographie du Maroc 18, 71-108.

Ruiz MatA, D. (1986): "La cerámicas fenicias del Castillo de Doña Blanca”, [en] Los fenicios en la Península Ibérica 1, Sadabell, 241-260.

Ruiz-Gálvez Priego, M. (1983): “Espada procedente de la ría de Larache en el museo de Berlín Oeste", [en] Homenaje a M. Almagro Basch 2, Madrid, 63-68.

SAnMArtí Greco, E. (1967): "Una factoría fenicia en el Marruecos atlántico", Ampurias 29, 301-303.

Sanmartín Ascaso, J. (1986): "Inscripciones fenicio-púnicas del Sureste hispánico (1)", [en] Los fenicios en la Península Ibérica 2, Sabadell, 90-91.

Schubart, H. (1986): "El asentamiento fenicio del S. VIII a.C. en el Morro de Mezquitilla (Algarrobo, Málaga)", [en] Los fenicios en la Península Ibérica 1, Sadabell, 59-83.

Souville, G.

(1964): "Une curieuse hache en bronze de la région des Beni Snassen", $B A \mathrm{M} 5$, 319-324.

(1986): “Témoignages sur l'âge du Bronze au Maghreb Occidental”, CRAI 103-113. (1988): "Les hommes du chalcolithique et du Bronze ont traversé le détroit de Gibraltar", [en] Actas del Congreso Internacional "El Estrecho de Gibraltar" 1, Madrid, 1988, 291-292.

Tarradell Mateu, M.

(1955): “El yacimiento púnico y romano de Mogador”, AEspA 28, 187.

(1958): "Notas acerca de la primera época de los fenicios en Marruecos", Tamuda 6, 71-88.

(1959): Lixus. Historia de la ciudad, Tetuan.

ThOUVENOT, R.

(1954): “Recherches archéologiques I Mogador”, Hespéris 41, 463-467.

(1954a): “Rapport sur l'activité de 1'Inspection des Antiquités du Maroc pendant l'année 1953", BCTH 1954, 46-57.

(1955-1956): "Rapport sur l'activité de l'Inspection des Antiquités du Maroc pendant les premiers mois de 1954”, BCTH, 202 (57-77). 